\title{
Motivation-Driven Learning and Teaching Model for Construction Education
}

Imriyas Kamardeen, (University of New South Wales, Australia)

\begin{abstract}
Quality learning outcomes are correlated with students' motivation to learn. Lecturers need to design courses that enthuse, inspire and motivate their students. But, this is a fundamental challenge facing many lecturers. A new motivation-driven learning and teaching model was developed to help lecturers in this regard. Its operationalisation, implementation and evaluation were conducted in a first year course in Construction Management degree through action research. Study findings suggest that the new model can help lecturers to improve overall teaching quality and student learning experience as it facilitates effective course delivery and stimulates student motivation to learn.
\end{abstract}

Keywords: Construction education, Pedagogy, Motivation, Student learning experience, Curriculum design, Teaching quality

\section{Introduction}

Motivation is an important factor in student learning; it is positively correlated with students' willingness to learn, high-level cognition, creativity and performance (Liu et al 2012). Ramsden (2003) maintained that quality learning outcomes are most likely to occur when students adopt a deep approach to learning, and active engagement and interactions are two important aspects in promoting deep approached to learning. However, self-motivation of students is a prime requirement for their active engagement and interactions. Freeman \& Blayney (2005) argued that these are more difficult to achieve in large classes, which have become the norm in many university courses due to increasing student numbers and limited resources.

Learning motivation is an essential issue that needs considerations when designing a course (Liu et al 2012). A vital part in the role of a lecturer should be to enthuse, inspire and motivate their students to learn (Kember \& McNaught 2007). Gavrin \& Novak (1999) critiqued that motivating students is one of the fundamental challenges facing lecturers. Many students work hard, but all too often the motivation is a grade rather than understanding. Many active learning methods can partially obviate this problem, however, once they leave the classroom, time pressure (often combined with poor study skills) can sap a student's motivation. As such, developing and implementing a motivating course has become a challenging task for university lecturers. To this end, this paper addresses the research question of "how can an effective motivation-driven learning and teaching strategy be developed and implemented in construction education?"

In addressing the research question, first a thorough literature review was conducted to identify factors that influence students' motivation to learn. Then a new motivation-driven learning and teaching model was developed based on the literature review findings. Following that an action research approach was adopted to operationalise and implement the model, and to validate its effectiveness/suitability to enhance student learning. Discussions in the paper are laid out in a logical order to reflect the above stages. First, the literature review findings on the factors that influence students' motivation are explored. Second, the new model of motivation-driven learning and teaching is introduced. Third, the process involved in operationalizing and implementing the model in a course is expounded 
followed by the analysis of its effectiveness, using a formal online student survey. Finally, conclusions are drawn.

\section{Critical Success Factors for Motivation-Driven Learning and Teaching}

Scholarly articles by researchers in higher education were reviewed for the purpose of identifying critical success factors for motivation-driven learning and teaching, and findings are summarised in here.

Kember \& McNaught (2007) identified five strategies to motivate students to learn:

- Encouraging students - students should be told that they have done well

- Displaying enthusiasm as a teacher by conveying a passion/fascination for the discipline and by showing sufficient interest in students - to get to know and establish a positive relationship with students

- Interesting and enjoyable classes - aim to make lessons interesting by entertaining teaching and engaging students

- Relevant materials - students should perceive that what is taught is relevant. Relevance can be established by using real life examples, drawing cases from current issues, giving local materials/examples and relating theories to practice

- Using a variety of teaching approaches involving active learning - learning occurs more through what students do than through what the lecturer says. Use a different teaching approach for lesson after lesson to avoid learning becoming monotonous

They further suggested that a variety in teaching approaches, involving active learning, is a feature of quality teaching, which naturally results in an innovative form of teaching. In addition to the most common types of university teaching: lectures, seminars and tutorials, several other forms can be used, which include: (1) projects, (2) student presentations, (3) case-based teaching, (4) problem-based learning, (5) role-play, (6) reflective journals, (7) experiential learning, (8) peer-tutoring, (9) games and simulations and (10) computerenhanced learning. Additionally, recently emerged adaptive e-tutorials technique is claimed to create a more advanced interactive learning environment that provides instant feedback to students on their learning progress and allows repeated attempts, thereby improving students' motivational level in learning (Beldagli \& Adiguzel 2010).

In a similar vein, Kember et al (2008) discussed findings of their interview survey with students from nine faculties in three universities on factors motivating and de-motivating student learning. Eight characteristics of a teaching and learning environment that motivate student learning in the order of importance are: (1) establishing relevance, (2) establishing interest, (3) allowing choice of courses/tasks so that interest can be followed, (4) learning activities, (5) teaching for understanding, (6) assessment of learning activities, (7) close teacher-student relationship and (8) sense of belonging between classmates. The most common reason given for a lack of motivation is that teaching is purely abstract or confined to theory and lacking applications. Without seeing applications which put the theory in context it becomes hard for students to grasp the meaning. They further suggested that lecturers map their courses to take account of these factors in building curriculums.

Edelson \& Joseph (2004) recognised a student's interest in a subject as a powerful motivator of learning as it provides four benefits:

- Natural appeal - interest describes a natural draw to certain activities

- Mastery goal orientation - interest leads to mastery goal orientation. When a learner perceives that certain knowledge or skills are useful to the pursuit of an interest, he or she is drawn to master the knowledge or skills, not just to demonstrate them

Kamardeen, I (2013) 'Motivation-driven learning and teaching model for construction education', Australasian Journal of Construction Economics and Building, 13 (1) 36-49 
- Persistence and effort - when a student is interested in a task, he or she is likely to expend more effort and persist longer at that task

- Strongly connected knowledge - individual interest carries an important cognitive benefit for learning because students have rich knowledge structures to build upon in their areas of interest

They further argued that learning materials, activities and social structures need to be designed carefully to capitalise on interest. Three pillars of the interest-driven learning framework proposed by them are:

- Creating relevance for learning materials

- Strengthening interest through the use of a variety of motivation

- Usefulness - when a student sees the usefulness and applications of acquired new knowledge to real world, that recognition of usefulness creates an inherent motivation to learn

In identifying teaching strategies for interest-driven learning, they included Goal-based Scenarios, Anchored Instruction, Concept Oriented Reading Instruction and Project-based Science. They further criticised that activities should be designed to establish relevance for students' areas of concern. For example, in adopting the Project-based Science strategy to teach air quality, learners can be asked to investigate the air quality in their own community. This will require them to learn the chemistry of air and its impact on the health of people, and to develop inquiry and data analysis skills.

In a structured fashion, Keller \& Suzuki (2004) proposed the ARCS model (acronym for attention, relevance, confidence and satisfaction) to assist educators in designing motivational tactics that can be integrated with teaching/learning strategies. The model suggests four conditions for motivational design of instruction:

- Attention - a lesson must gain and sustain the learner's attention by incorporating a variety of tactics to gain learner attention by the use of interesting graphics, animation, any kind of event and stimulating inquiries, and varying approaches and pace are important for this purpose

- Relevance - it is necessary for learners to perceive the instructional requirements to be consistent with their goals, compatible with their learning styles and connected to their personal interests and experiences

- Confidence - this is accomplished by helping students establish positive expectancies for success and attribute their successes to their own abilities and efforts

- Satisfaction - this is necessary in order for learners to have positive feelings about their learning experiences. This means extrinsic reinforcements such as positive rewards and recognitions must be used

In exploring structured lectures, Jenkins (1992) suggested a number of tactics to encourage student learning, viz:: (1) lectures should be limited to short bursts, (2) after or before each short burst of lecturing, brief learning tasks should be introduced, involving the application of principles and discussions between students in twos or threes, (3) the learning tasks would work best if they are varied in format and process, engaging, open-ended, but possible to tackle and discuss in a few minutes, (4) it is necessary to provide handouts, course guides or guides to reading so that course material is accessible to students outside class, and (5) good social relationships between students, and between students and the lecturer certainly help. If students work in small groups in projects, it will help if they sit in the same grouping in the lecture.

Kamardeen, I (2013) 'Motivation-driven learning and teaching model for construction education', Australasian Journal of Construction Economics and Building, 13 (1) 36-49 


\section{Developing a Motivation-Driven Learning and Teaching Model}

The review above identified six essential pillars for a motivation-driven learning and teaching practice, including: (1) establishing relevance to the real world in designing course materials, (2) adopting relevant assessments and providing balanced feedback promptly, (3) utilising a mix of active learning strategies, (4) creating an interactive classroom/learning atmosphere, (5) recognising students' efforts and achievements constantly and openly, and (6) building close student-lecturer relationships. A range of tactics were identified in literature as means to achieve each of these pillars and a preliminary model of motivation-driven learning and teaching was developed. Then, a critical review of the model was conducted with a senior academic in the author's discipline who has won the Vice-Chancellor's Teaching Award, the Dean's Teaching Award and several school level commendations for teaching quality. The peer approved of all the six pillars and their corresponding tactics. However, he suggested another important element that has to be a part of all these pillars; continual improvement. The effectiveness of tactics used for each pillar of the model in different courses should be measured and used for continual improvement of teaching. He further suggested a couple of techniques for measuring the effectiveness: maintaining a teaching logbook to record what worked well and what did not in every class and maintaining a logbook of qualitative student feedback that states students comments and the author's responses. With these, the model was finalised as illustrated in Figure 1. The model can work as an overall framework for teaching practice; however its operationalisation in individual courses is influenced by the context of the course, course aims, expected student learning outcomes and the student cohort. The next section discusses the research method adopted in validating the model.

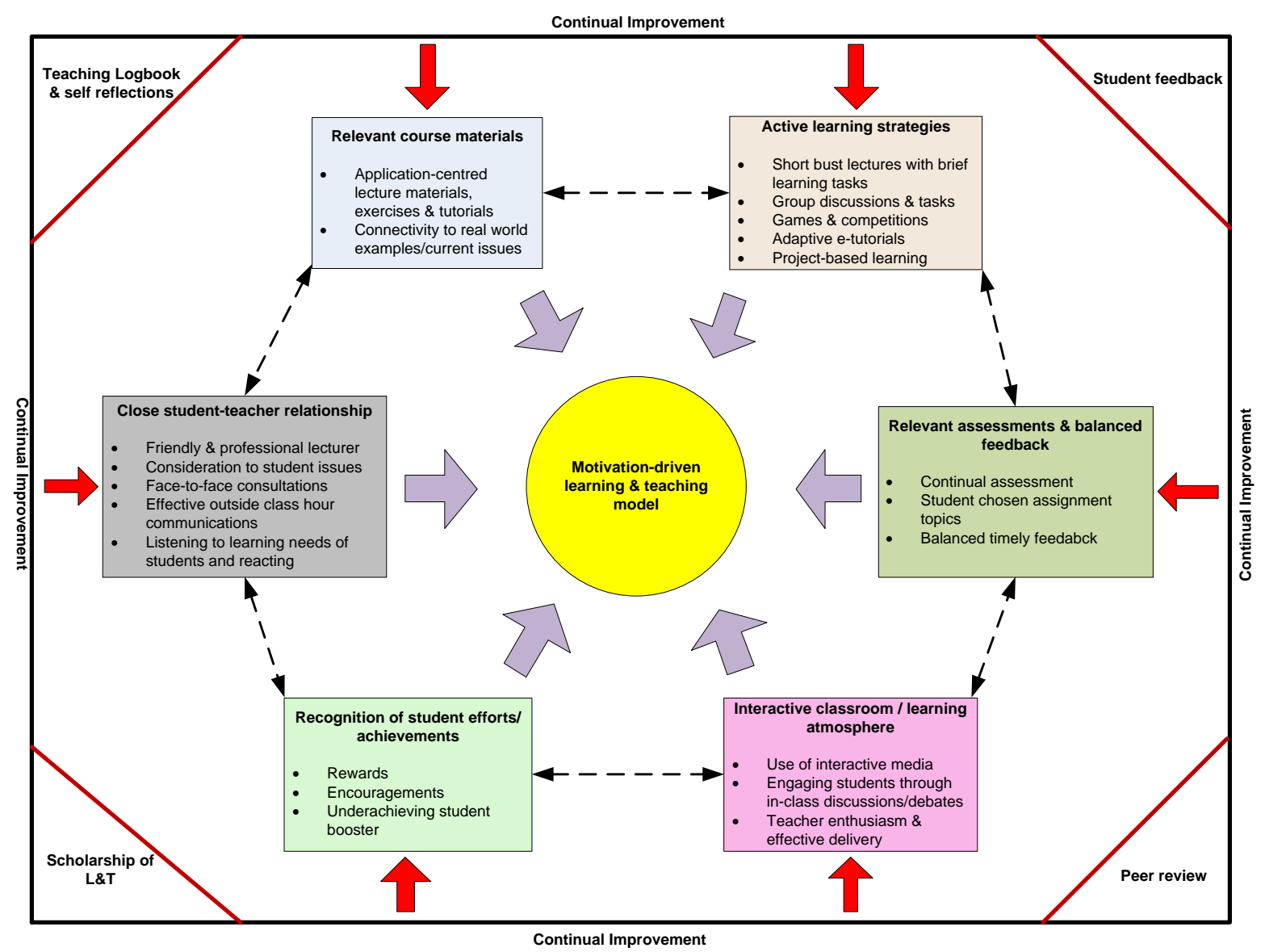

Figure 1 Motivation-driven learning \& teaching model 


\section{Research Method}

The study adopted an action research approach to validate the model. Action research is a process in which participants examine their own educational practice systematically and carefully, using the techniques of research (Ferrance 2000). Action research is a systematic process that allows educators to try out different ways of doing things in the classroom, until they find something that really works for them and students (Laycock \& Long 2009). Mertler \& Charles (2008) argued this approach is better for lecturers because it:

- deals with their own problems, not someone else's

- can start now-or whenever they are ready_providing immediate results

- provides them with opportunities to better understand, and therefore improve, their educational practices

- provides educators with alternative ways of viewing and approaching educational questions providing a new way of examining their own practices

A first year core course, Construction and Property Economics, from the Bachelor of Construction Management and Property degree program was chosen for the study. The selection was dictated by the nature of the course and the class, viz.:

- The class has always had student enrolments close to a hundred, causing challenges for the lecturer in terms of interaction, classroom management, assessment and feedback.

- Student feedback on the lecturer's teaching quality has been less-than-favourable in the past years.

Three stages were involved in undertaking the action research towards validating the model: (1) the model was operationalised and implemented in the course over a full teaching session, (2) student feedback on their learning experiences was received through an online questionnaire survey at the end of the session, and (3) survey data was analysed, findings were compared with previous years and reflections were made. Following sections elaborate on these stages vividly.

\section{Operationalisation and Implementation of the Model}

The author implemented the above learning and teaching model in the course, which covers such topics as design economics, project economic appraisal, cost benefit analysis for public projects and the construction industry and the national economy. The author had taught the course in the previous five years using the traditional model of delivery, involving lectures, tutorials, assignments and exams. The author's experience of teaching the same course over the past years suggested some insights/reflections that are also crucial for redesigning the delivery mode. These are:

- Students are more grade-focused than learning-oriented. They appear interested in learning tasks and active participation in lectures or tutorials if these are directly related to an assessment or grade

- Students favour the continual assessment system over the final exam system

- Students prefer hands-on tasks over formal written submissions

- Flexibility, informality and simplicity are three features that students want in their studies

In light of the proposed new model and insights from previous experience, the author implemented a motivation-driven teaching practice for the course, quite differently to past years. The account below explains how the six pillars of the proposed motivation-driven learning and teaching model were operationalised.

Kamardeen, I (2013) 'Motivation-driven learning and teaching model for construction education', Australasian Journal of Construction Economics and Building, 13 (1) 36-49 


\section{Designing Relevant Course Materials}

In designing lecture materials, exercises and tutorial tasks, cases were drawn from real world situations. For example: when discussing economics of building designs interactive videos and actual house plans from the Australian home building industry were used; in teaching project economic appraisal examples from daily lives of students and local property development projects were utilised; the proposed East Coast High Speed Rail Network in Australia was chosen for exercising cost benefit analysis for public projects; and recent national and state policies, proposals and projects were weaved into discussions on the dynamic connections between the national economy and the construction industry.

\section{Adopting Blended Active Learning Strategies}

A blended delivery strategy was adopted, which contained lectures, tutorials and exercises, discussions and debates, competitions, projects, class presentations and adaptive etutorials.

- The lectures were broken down into short bursts and a variety of brief learning tasks were given to students in between the bursts to provoke interactions and discussions. The lecture notes were made available to students in advance of lectures, which enabled them to write additional self-notes during lectures. Also, students were given time or pauses to allow them jot down extra notes against points in the lecture slides.

- Tutorials and exercises were designed so that the classroom theories were applied to problem solving. Students were encouraged to work in small informal groups in the tutorial classes, discuss and debate solutions for problems given. An additional layer was added in that competitions between student groups were conducted and winning groups/students were awarded prizes.

- A project-based assignment was given to students in which students worked in small groups and each group explored a different subject matter. Continual consultations were in place to guide students in their self-directed learning. The submission consisted of a written report and a class presentation.

- An advanced form of eLearning, known as adaptive eLearning was also practised. An adaptive e-tutorial using a special software platform, called Smart Sparrow ${ }^{\mathrm{TM}}$, was made available to help students to prepare for a class test; this approach boasted with improved interactivity, real-time feedback and flexibility.

\section{Applied Assessments and Prompt Feedback}

A continual assessment system was used in the course with two class tests and a group assignment. Connections between lectures, tutorial contents and impending class tests were constantly made to spice up students' attention. An opportunity for practice tests was provided through the adaptive e-tutorial portal. The utilisation of the adaptive e-tutorial helped students tremendously to understand concepts and apply them to different situations, as indicated by students.

The assignment was entirely project-based, involved research and analysis, and learning was directed by students according to their learning need, pace and convenience. Clear assessment criteria were provided in advance to facilitate student learning. Students were expected to study and analyse real world cases/situations relevant to their topic for better grades. Intermediate consultations and feedback were held to check on the learning progress. Final submissions included a written report and a class presentation. Because the assignment covered a range of topics, students were exposed to twenty different discussions that were not covered in the scheduled lectures. This added more value to students' knowledge bases and eradicated monotony. 
Assessment results and feedback were released within a few weeks after the assessment. This allowed students to understand their standing and areas that need improvements. Balanced and prompt feedback on students' efforts and submissions was provided to sustain student motivation. The continual assessment scheme was a good way for having multiple opportunities for formal feedback and drive students to improve on their performance.

\section{Classroom Atmosphere and Interactive Learning Environment}

Several tactics were used to make the classroom atmosphere and the learning interactive. First, the author showed enthusiasm and a passion for teaching the students by being active, walking around the class, talking vibrantly and enthusiastically engaging with students with a positive attitude. At times, entertaining students with jokes helped to eliminate boredom. During the delivery of lecturers, students were constantly engaged through short learning tasks and by both selectively and voluntarily asking students for their inputs. Interactive media such as graphics, animations, simulations and documentaries/digital stories were utilised to reinforce the lectures. In tutorial classes, students were invited to come to the board and explain their answers to fellow students, who were suggested to compare and contrast their answers. Whenever variations occurred, discussions emerged. These made collective learning possible and peer review took a strong place. The lecturer's evaluation and feedback at this juncture acted to reinforce their understanding and clarify grey issues. Moreover, three competitions were held in tutorial tasks, which helped to retain students' focus and engagement in learning. In the projectbased learning task, dedicated time slots were allocated for face-to-face consultations between group members and with the lecturer. Moreover, discussion forums and file sharing arrangements were set up on the online learning platform, Blackboard. Apart from the usual online platform that is used at the university, the author utilised the adaptive eLearning platform, Smart Sparrow ${ }^{\mathrm{TM}}$, which improved flexibility, interactivity, real-time feedback and stimulating students' interest, as evidenced in qualitative feedback received on that particular tactic.

\section{Recognising Student Efforts and Achievements}

Several tactics were used to stimulate students' attention, confidence and motivation through recognition of students' efforts and achievements. Very basically, students who voluntarily contributed to learning tasks during lectures, exercises and tutorial classes were openly encouraged with positive remarks. Prizes were awarded to winners of the competitions in three occasions. And, the winners were publicised and encouraged before the class. Bonus points were made available for completing certain difficult exercises during tutorial classes. These were separate from the prizes for competitions. Individual emails were sent to high performing students in class tests, encouraging them to continue the good work. And, comforting emails were sent to underachieving students and additional support was also provided to them. Special consultation hours were dedicated every week for additional support.

\section{Student-Lecturer Relationship}

In order for students to be interested in a course, they should like it. For students to like a course, the lecturer must be likeable to them first. Strengthening the lecturer-student relationship in a professional manner is therefore paramount. The author practised the following habits in that venture:

- The author put an effort in knowing most students by their names and their study circumstances individually. This enabled close interactions throughout the course and students liked it when they are known to the lecturer personally.

- The author was friendly and kind, yet professional with every student. Even some disruptive and rude students were calmed down by a soft approach. 
- Paying good attention to individual circumstances of students is crucial. The author took every effort to make students who had study disabilities or personal issues feel that their problems were considered promptly and appropriately.

- Swiftly responding to students' emails and enquiries increased students' confidence in the lecturer

- Informal conversations about daily issues during breaks were helpful to get to know students better.

\section{Effectiveness of the Model}

The effectiveness of the proposed new motivation-driven learning and teaching model, which was mirrored in the above teaching practice, was evaluated through a formal feedback system used by the author's university. At the conclusion of the teaching session, the university conducted an anonymous online questionnaire survey amongst students to receive their feedback on the quality of teaching of lecturers. The survey evaluated the following nine quality attributes:

- Effectiveness of communication

- Stimulating students' interest in the subject

- Encouraging critical thinking

- Providing feedback on students' progress

- Interactivity in delivery

- Helpfulness and support to students' learning

- Course structure

- Lecturer's enthusiasm

- Encouraging students to perform

The questionnaire contained ten questions related to the attributes above and student responses to the questions were collected on a 6-point Likert scale. Qualitative comments were also received for the following two questions:

- What were the best features of this lecturer's teaching?

- How can this lecturer's teaching be improved?

All students who enrolled in the course (total of 85 students) were invited to participate in the online survey but only 40 students responded, making a response rate of $47 \%$. Table 1 shows the summary of the survey results. Furthermore, these survey results were compared with the corresponding results of previous years' surveys for the same subject when the motivation-driven teaching practice was not in place but the topic coverage and the expected learning outcomes were the same. The mean response for each question for this year was higher than the values for previous years. The comparison chart in Figure 2 better illustrates this. The $\mathrm{X}$-axis represents the survey questions and the $\mathrm{Y}$-axis represents the corresponding mean student rating for each question for the years considered. The survey results were further analysed in conjunction with the qualitative comments provided by students. Given the nature of qualitative comments, the findings are discussed under five themes in the sections below. 


\begin{tabular}{|c|c|c|}
\hline Survey question & $\begin{array}{l}\text { Mean } \\
\text { rating }\end{array}$ & $\begin{array}{l}\text { Standard } \\
\text { deviation }\end{array}$ \\
\hline $\begin{array}{l}\text { 1. This lecturer communicated effectively with students (e.g. He / She } \\
\text { explained things clearly). }\end{array}$ & 4.9 & 1.2 \\
\hline $\begin{array}{l}\text { 2. This lecturer stimulated my interest in the subject matter he/she was } \\
\text { teaching. }\end{array}$ & 4.9 & 1.1 \\
\hline 3. This lecturer encouraged me to think critically. & 5.0 & 1.1 \\
\hline 4. This lecturer provided feedback to help me learn. & 4.8 & 1.2 \\
\hline $\begin{array}{l}\text { 5. This lecturer encouraged student input and participation during } \\
\text { classes. }\end{array}$ & 5.2 & 1.0 \\
\hline 6. This lecturer was generally helpful to students. & 5.1 & 1.0 \\
\hline 7. The lecturer was well prepared and structured the subject matter well. & 5.2 & 1.0 \\
\hline 8. The lecturer was enthusiastic about the material he/she was teaching. & 5.3 & 1.0 \\
\hline 9. The lecturer encouraged students to do their best work. & 5.3 & 1.0 \\
\hline 10. Overall, I was satisfied with the quality of this lecturer's teaching. & 5.1 & 1.1 \\
\hline
\end{tabular}

Table 1 Summary of survey results

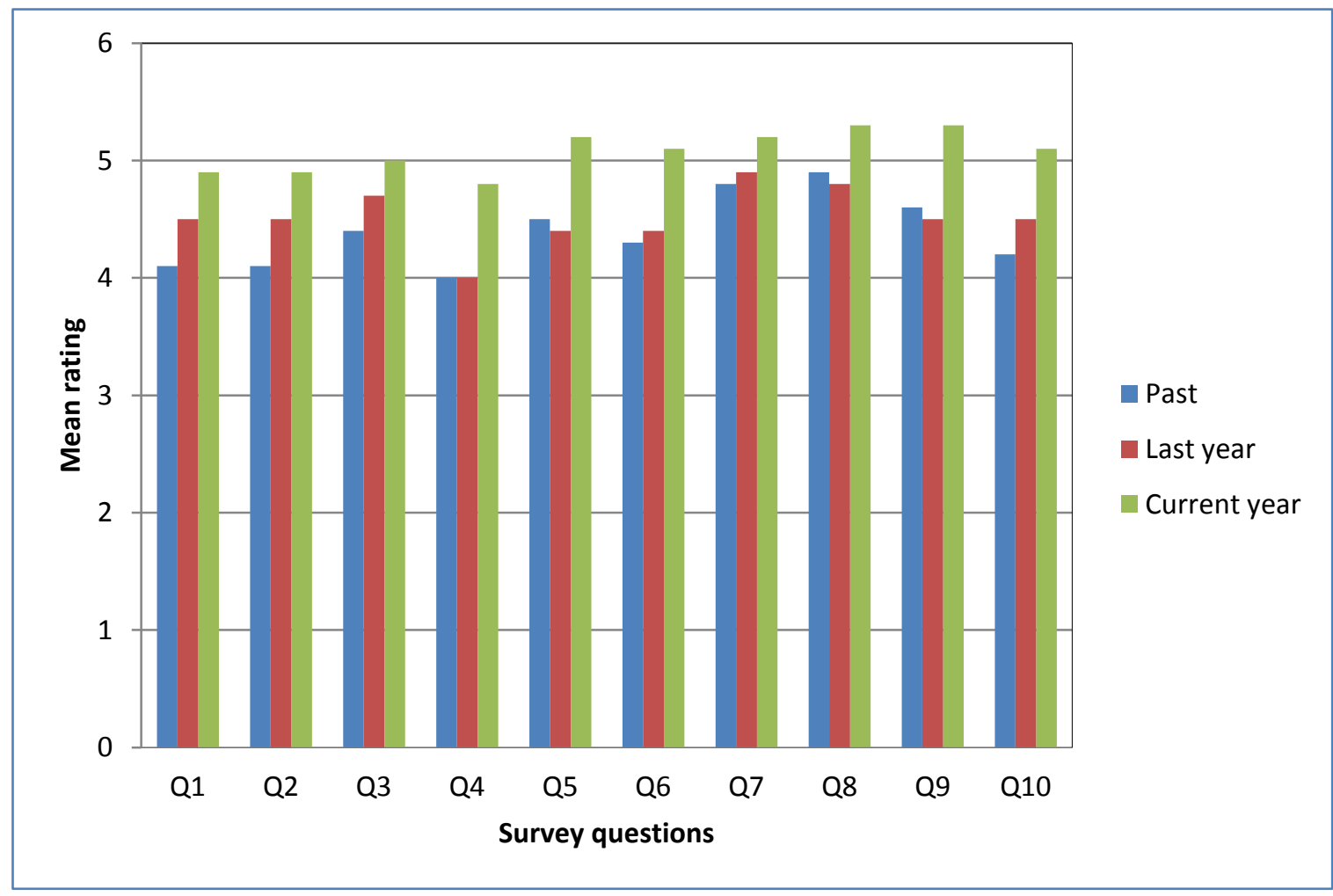

Figure 2 Comparison chart

\section{Effectiveness of Course Delivery}

The effectiveness of course delivery was measured by four attributes, including: lecturer's communication effectiveness, interactivity in delivery, course structure and lecturer's enthusiasm. The individual mean ratings received for these attributes were accumulated as shown below and an overall effectiveness indicator of 5.15 (out of 6.0) was yielded.

Q1: This lecturer communicated effectively with students (e.g: he/she explained things clearly) $=4.9$ 
Q5: This lecturer encouraged student input and participation during classes. $=5.2$

Q7: The lecturer was well prepared and structured the subject matter well. $=5.2$

Q8: The lecturer was enthusiastic about the material he/she was teaching. $=5.3$

Cumulative mean rating for 'effectiveness of course delivery' $=5.15$

Furthermore, the qualitative comments were analysed to identify what aspects of course delivery resulted in obtaining the high overall rating. It is evident that students look for five elements in appreciating effectiveness of course delivery, which are:

- lecturer's knowledge of and experience in the subject matter

- Well organised and clear lecture notes and tutorial exercises

- Variety and innovation in teaching style

- Interactions and student engagement in classes

- Enthusiastic, cheerful and easy-going nature of the lecturer

Below are some of the direct student quotes, relating to this indicator, for the question "what were the best features of this lecturer's teaching".

Very good academic knowledge of the subject; helpful when asked questions

Very well organised with lecture notes and tutorial exercises

Lecture notes were very good and teaching style was awesome

Good, clear teaching skills, able to deliver the course outline well and keep the lectures productive

The lecturer used the most modern methods of teaching and interactive learning rather than sitting on a stool and reading through boring lecture slides

The variety of teaching styles used was excellent; engaging and tried to get everyone involved

Always taught with a smile; interested in the education of his classes; innovative in his educational methods

This lecturer made an effort to spend extra time during the lecture to focus on aspects of the course which were either important or difficult to understand in order to ensure that students did not get lost or confused. This lecturer was also very good at minimising disruptions caused by talkative students during the lecture

\section{Stimulating Students' Motivation to Learn}

The lecturer's ability to stimulate and improve students' motivation to learn was measured by three attributes, including: stimulating interest in the subject, encouraging critical thinking and encouraging best performance. The ratings received for the corresponding questions in the survey were aggregated, which resulted in an overall mean rating of 5.07 out of 6.0.

Q2: This lecturer stimulated my interest in the subject matter he/she was teaching $=4.9$

Q3: This lecturer encouraged me to think critically $=5.0$

Q9: The lecturer encouraged students to do their best work $=5.3$

Cumulative mean rating for 'stimulating students' motivation' $=5.07$

As in the previous indicator, the qualitative comments were studied to identify what students perceive as motivating factors. Four aspects in the course seem to have motivated student learning: 
- Nature of tutorials and exercises (real-world oriented; designed as competitions and games)

- Use of adaptive eLearning tasks, which provided improved flexibility, interactivity and reflective learning opportunities

- Incentives/rewards for better performance

- Personal encouragements given by the lecturer

Some direct student quotes on these are as follows (these were given to the question "what are the best features of this lecturer's teaching"):

Tutorial exercise games were best

e-tutorials really helped me to prepare for exams

Giving incentives to students is very encouraging as it makes the subject more fun and enjoyable

Encouraged student learning and participation with bonus points

Friendly approach and encouraging attitude; very involved with the class and is enthusiastic about the material taught

\section{Feedback and Learning Support}

The level of learning support offered to students was measured by two attributes, including: feedback and helpfulness. The aggregation of the ratings received for these individual attributes resulted in 4.95 out of 6.0 .

Q4: This lecturer provided feedback to help me learn $=4.8$

Q6: This lecturer was generally helpful to students $=5.1$

Cumulative mean rating for 'feedback and learning support' $=4.95$

Being helpful, approachable and prompt in replying enquires/questions have supported student learning in the course, as evidenced by the following direct quotes of students (given as answers to the question "what are the best features of this lecturer's teaching"):

Enthusiastic, cheerful and always happy to help

Enthusiastic attitude and willingness to help

Helpful and interactive

Very personal, and provided a lot of extra assistance for students

The lecturer seemed eager to help students and he put together slides that were helpful and easy to understand

The lecturer was a great teacher and assisted in my learning wherever possible. He was also very prompt in responding to email enquiries regarding course work

The author believes that the slightly low overall rating (4.95) for this indicator, as opposed to other indicators, maybe due the less-adequacy of formal written feedback given to students.

\section{Overall Student Learning Experience}

The overall student learning experience was computed by aggregating the mean ratings for all the nine attributes (Q1-Q9) that collectively characterise teaching quality. Hence, the overall mean rating for Q1-Q9 was computed to be 5.08, which is almost the same as the rating for Q10. On the whole, it is evident from the survey findings that the proposed motivation-driven learning and teaching model has been effective in improving teaching quality and student learning experience. An all-encompassing comment on this by a student reads as follows: 
"The lecturer has clearly defined the course to make it as interesting, engaging and useful as possible. He is happy to help students out and he explicitly defined what was required for assessment tasks to help students prepare. He provided us with plenty of materials of revision, which not many lecturers do. Moreover, he is very knowledgeable and I can walk out of every one of his lecture knowing something new"

\section{Potential Improvements}

Continual improvement of tactics is a key element in the proposed motivation-drivel learning and teaching model. Hence, students' suggestions for potential improvements were looked at attentively. The comments on this account show three patterns. Thirty-two per cent of the respondents felt that there is no need for further improvements of the methods used. Responses from another twenty-two per cent of participants suggest that more case studies and practical exercises would be better. The rest of the comments were related to communication. The author is a non-native English speaker and this has inevitably resulted in his accent being different, which attracted some comments. On a positive outlook, the author has set out to revamp the course and delivery in the future on account of all these comments.

\section{Challenges for Implementation}

The implementation of the motivation-driven learning and teaching model has resulted in a good learning experience for students and the student feedback is promising for the lecturer. Nonetheless, the lecturer had to overcome a few challenges in successfully implementing it, as discussed below.

\section{Pedagogical Inputs}

The lecturer's pedagogical inputs, time and effort invested were more in this approach than that of in the traditional approach. While this was a challenging part, it has been a core element in attracting better reviews from students. The experience of implementing the new learning and teaching model discussed in the paper endorses that the extra effort will pay-off and is worth the investment.

\section{Students' Negative Perceptions}

Students' perceptions and feelings about the benefits of various learning tasks used in a course will influence their level of motivation, participation, learning process and thereby their feedback on teaching quality. Hence, for a successful implementation of a motivational strategy, the lecturer should convince students/learners that participation will provide benefits worth the time and effort. Assessments can be used as the point of reference; doing so will stimulate motivation to participate. In this particular case, bonus marks were provided for some difficult tutorial tasks. Also, the adaptive e-tutorial was linked to a class test in that the e-tutorial was provided to students as a supplementary resource to prepare for the test. These tactics encouraged students to actively participate in practising and learning.

\section{Technology}

As indicated above, an adaptive-eLearning task was utilised in the course to enhance prompt feedback and student learning. Most of the widespread eLearning systems that are used in universities do not have adaptive eLearning capabilities. It was therefore necessary to use a suitable adaptive eLearning system. This was additional to the eLearning platform that was used in the course. The lecturer had to climb a learning curve and dedicate extra time and effort to familiarise himself with the usage of the new technology.

\section{Conclusions}

Traditional instructional models regard learning and teaching as a process-oriented, mechanical practice. However, effective student learning occurs when instructional models incorporate social and psychological dimensions in designing curriculums. Motivation of students to actively engage in learning is a strong psychological force that can deliver

Kamardeen, I (2013) 'Motivation-driven learning and teaching model for construction education', Australasian Journal of Construction Economics and Building, 13 (1) 36-49 
desired outcomes for students and lecturers. It is the responsibility of lecturers to motivate their students to achieve the high expectations they have of them. The presence of seven elements in course designs will help lecturers to exercise a motivation-driven learning and teaching practice, which include:

- Relevant course materials that demonstrate applications of theories to real world issues

- A blended delivery strategy with a variety of active learning tactics

- Relevant and application-focused assessments, and prompt and balanced feedback on student performance

- Recognition of student performance through rewards and encouragements

- Interactive classroom atmosphere, filled with intellectual engagement of students and enthusiasm of the lecturer

- Close yet professional relationships between students and the lecturer

- Continual improvement of the tactics used to achieve the above six elements on account of student feedback, peer review, self reflections and scholarships of learning and teaching

The operationalisation of this model of learning and teaching is highly context specific. Lecturers should consider graduate attributes, course aims and expected learning outcomes in developing an effective teaching plan for a given course. Moreover, advanced planning is essential for an effective operationalisation of the motivation-driven learning and teaching strategy and the implementation could demand extra efforts from lecturers. However, the extra efforts would be rewarded pedagogically and in the form of improved student learning and favourable feedback on teaching quality.

\section{References}

Beldagli, B. \& Adiguzel, T. (2010) 'Illustrating an ideal adaptive e-learning: a conceptual framework', Procedia-Social and Behavioural Sciences, 2 (2), 5755-61

Edelson, D.C. \& Joseph, D.M. (2004) 'The interest-driven learning design framework: motivating learning through usefulness', Proceedings of the 6th international conference on Learning sciences, 166 - 7, Retrieved from http://dl.acm.org/citation.cfm?id=1149145. [14 Aug 2012]

Ferrance, E. (2000) Action research. Brown University, Retrieved from http://www.alliance.brown.edu/pubs/themes ed/act research.pdf. [2 Dec 2012]

Freeman, M. \& Blayney, P. (2005) 'Promoting interactive in-class learning environments: a comparison of an electronic response system with a traditional alternative', Proceedings of the $11^{\text {th }}$ Australasian Teaching Economics Conference, 11-12 July, University of Sydney, 2334. Retrieved from

http://ses.library.usyd.edu.au/bitstream/2123/199/1/03\%20Freeman\%20Blayney.pdf. Sept 2012]

Gavrin, A.D. \& Novak, G.M. (1999) 'What is physics good for? motivating students with online materials', Retrieved from http://serc.carleton.edu/resources/14235.html. [30 Sept 2012]

Jenkins, A. (1992) 'Encouraging active learning in structured lectures', Gibbs, G. (ed.), Improving the Quality of Student Learning, Technical and Education Services Ltd, Bristol, 46-58

Keller, J. \& Suzuki, K. (2004) 'Learner motivation and e-learning design: a multi-nationally validated process', Journal of Educational Media, 29 (3), 229-39.

Kember, D. \& McNaught, C. (2007) Enhancing University Teaching, Routledge, London

Kamardeen, I (2013) 'Motivation-driven learning and teaching model for construction education', Australasian Journal of Construction Economics and Building, 13 (1) 36-49 
Kember, D., Ho, A. \& Hong, C. (2008) 'The importance of establishing relevance in motivating student learning', Active Learning in Higher Education, 9 (3), 249-63

Laycock, D. \& Long, M. (2009) Action Research? Anyone can! IBSC Global Action Research Project. Retrieved from

http://drij.uitm.edu.my/DRJJ/MATRIC2010/5.\%20Anyone can Action Research-DRJJ02022010.pdf. [2 Dec 2012]

Liu, E. Z., Lin, C., Jian, P. \& Liou, P. (2012) 'The dynamics of motivation and learning strategy in a creativity-supporting learning environment in higher education', The Turkish Online Journal of Educational Technology, 11 (1), 172 -80

Mertler, C.A. \& Charles, C.M. (2008) 'Introduction to education research, 6th Ed., Allyn \& Bacon Boston, Mass

Ramsden, P. 2003, Learning to teach in higher education, $2^{\text {nd }}$ Ed., Routledge, London 